\title{
PASAPORTES DE CARIDAD: LAS "CARTAS DE GUÍA" DE LAS MISERICORDIAS PORTUGUESAS (SIGLOS XVII-XIX)
}

\author{
María Marta Lobo de Araújo - Alexandra Patrícia Lopes Esteves \\ Universidade do Minho
}

\begin{abstract}
RESUMEN: El presente trabajo estudia las cartas de guías, emanadas de las Misericordias portuguesas entre los siglos XVII y XIX. A través de su estudio se pretende destacar su importancia y significado para los sectores de la población más necesitados. Sin estatuto de obra de caridad, el despacho de cartas de guía se desarrollaba en todas las Santas Casas estudiadas, actuando entre ellas a través de un mecanismo de relevo. Las cartas de guía eran documentos entregados a los pobres que se hallaban de tránsito o que comenzaban un viaje, abriendo las puertas de la caridad a la institución de asistencia más próxima, conformándose, de esta manera, una cadena de solidaridad en torno a los más desfavorecidos, formada por toda la red de Misericordias portuguesas.
\end{abstract}

PALABRAS CLAVE: Portugal, Edad Moderna, pobreza, Misericordias.

ABSTRACT: This work goes through the "cartas de guia" given by the Portuguese "Misericórdias" between the 17th and the 19th centuries and intends to show their meaning and importance to the needy. In spite of not being formally considered charity work, the "cartas de guia" were given by all the "Santas Casas" we have studied and they were highly important to the poor. These letters were a common practice in these institutions and they were given to the poor who were moving or who intended to move, and they also opened the doors of charity in the nearest charity institution. There the poor were given the essential (goods) and a "carta de guia" was given to them. This procedure was repeated until the poor arrived at their destiny. This way it was possible to connect all the links in the solidarity chain formed by all the "Misericórdias" in favour of the poor.

KEYWORDS: Portugal, Modern Age, poverty, Misericordias.

\section{INTRODUCCIÓN}

El auxilio a los que se encontraban de viaje o necesitaban cobijo resultaba fundamental para un importante segmento de la sociedad. Sin esta ayuda, los pobres no podrían desplazarse, puesto que los viajes resultaban muy costosos. En este importante aspecto de la asistencia social participaban activamente las 
Misericordias portuguesas, posibilitando a los más desfavorecidos la realización de sus viajes y contribuyendo a aminorar sus precarias condiciones de vida. Como señala Maria Antónia Lopes, los pobres que solicitaban las cartas de guía eran "frequentemente assimilados a peregrinos", categoría que les abría las puertas de la caridad.

Debemos aclarar, antes de continuar con nuestro estudio, que otras instituciones además de las Misericordias, ofrecían igualmente cartas de guía. El hospital del Espíritu Santo de Portel incluía entre sus deberes la ayuda a los viajeros, constituyéndose en una de sus principales preocupaciones desde el punto de vista asistencial $^{2}$. En ese ámbito trabajaba en coordinación con la Misericordia de la villa, que también ofrecía una limosna a aquellos que necesitaban efectuar un viaje.

Además de estas instituciones, también los obispos se implican con estas obras de caridad, posibilitando, a través de las cartas de guía, que muchos pobres pudiesen realizar el desplazamiento que tanto deseaban.

Las cartas de guía eran solicitadas mediante una petición por escrito dirigida a la Santa Casa. Como generalmente los pobres no dominaban la escritura, recurrían a aquellos que conocían este arte para poder entrar en contacto con la cofradía.

A pesar de haber desempeñado un papel de gran relevancia como auxilio a la pobreza, las cartas de guía no han constituido hasta la fecha objeto particular de estudio. Salvo raras excepciones ${ }^{3}$, pocos son los trabajos producidos dentro del campo de investigación de la asistencia que destacan y reconocen su importancia y función.

La asistencia a viajeros era una práctica seguida en todas las Misericordias, si bien alcanzaba proporciones muy variadas entre estas instituciones.

El comportamiento de los ricos con respecto a los pobres durante la Época Moderna fue un tanto contradictorio: si por un lado los protegían a través de los actos de caridad, por otro, los marginaban, repudiándolos. La limosna no estaba al

${ }^{1}$ Lopes, M. A. (2000). Pobreza, assistência e controlo social. Coimbra (1750-1850), vol. II, Viseu: Palimage Editores, p. 82.

${ }^{2}$ Para el estudio de la acción del hospital de Portel en el socorro a los que necesitaban viajar o se hallaban en tránsito consúltese el trabajo de Maria Marta Lobo de Araújo, "O hospital do Espírito Santo de Portel na Época Moderna” (2003). Cadernos do Nororeste, 20 (1-2), pp. 370-371.

${ }^{3}$ El trabajo de Maria Antónia Lopes confiere autonomía a esta forma de caridad y la destaca como un sistema de ayuda importante para los pobres de Coimbra. Vid. Pobreza, assistência e controlo social..., pp. 82-83. 
alcance de todos. Por tal razón, muchos de los que solicitaban ayuda no eran tenidos en cuenta, porque no se les consideraba merecedores de ella.

Para el hombre del Antiguo Régimen socorrer al pobre era acercarse a Cristo y contribuir a la redención de sus pecados. Fue desde la Edad Media cuando, a través de la caridad y del amor a los más desfavorecidos, se buscaba llegar más cerca de Dios y capitalizar beneficios que posibilitasen la felicidad eterna ${ }^{4}$. Los propios Evangelios aconsejan los actos de amor al prójimo y demuestran la necesidad de las prácticas de caridad ${ }^{5}$.

Pero si para los pobres la limosna significaba el alivio -aunque temporal- de sus miserias - la caridad practicada podía ser también duradera y prolongarse incluso durante varias décadas ${ }^{6}$, para los poderosos representaba, sobre todo, ventajas espirituales, sociales e incluso políticas ${ }^{7}$. La limosna debería ser practicada simplemente con la esperanza de una recompensa espiritual, sin embargo, los poderosos se servían de ella para incrementar su poder al mismo tiempo que ejercían el control sobre los pobres ${ }^{8}$.

Todas las ocasiones servían para la práctica de la caridad. Por eso se practicaba en vida, en momentos especialmente relevantes del calendario litúrgico -la Pascua, la fiesta de la Visitación, los Santos y la Navidad-, o en la hora de la muerte, cuando se cumplía el testamento.

La caridad se ejercitaba también en la vida cotidiana, cuando en la calle, a la puerta de casa o en ciertos días de la semana, los pobres se hacían presentes y pedían limosna. Era también frecuente que los ricos distribuyesen donativos en las puertas de sus palacios para conmemorar alguna fecha festiva o para implorar por

4 Consúltese a propósito de lo dicho: Dos Guimarães SÁ, I. (2001). As Misericórdias portuguesas de D. Manuel I a Pomba., Lisboa: Livros Horizonte.

5 (1999). Bíblia Sagrada, Lisboa: Editorial Bíblica, pp. 32-46.

${ }^{6}$ A propósito de la caridad ejercida durante varias décadas a un mismo sujeto. LOBO DE ARAúJO, M. M. (2003). Rituais de caridade na Misericórdia de Ponte de Lima (séculos XVII-XIX). Braga: Santa Casa da Misericórdia de Ponte de Lima, pp. 176-182.

${ }^{7}$ Para esta temática véase: Dos GuIMARÃES SÁ, I. (2002). "Estatuto social e discriminação: formas de selecção de agentes e receptores de caridade nas Misericórdias portuguesas ao longo do Antigo Regime". En Leandro, M. E.; Lobo de Araújo, M. M.; Silva Costa, M. (Org.). Saúde. As teias da discriminação social. Actas do Colóquio Internacional Saúde e Discriminação Social. Braga: Instituto de Ciências Sociais, p. 307.

${ }^{8}$ VAn LeEuwen, M. H. D. (1994). "Logic of charity: poor relief in Preindustrial Europe". Journal of Interdisciplinary History, 24-4, pp. 589-613. 
el alma de un ser querido ${ }^{9}$. Se realizaban también en ciertos días de la semana; el duque de Braganza D. Juan II, distribuía con frecuencia en persona limosnas los viernes a todos los mendigos que se encontraban frente a su palacio de Vila Viçosa ${ }^{10}$.

Aunque situados en polos diametralmente opuestos, pobres y ricos, cuando se encontraban en estos actos, estrechaban lazos. Desarrollando actos de gratitud, la caridad originaba un intercambio de favores entre pobres y ricos, sirviendo a las elites para reforzar su poder. Como se trataba de una relación desigual, el comportamiento que se esperaba de los pobres era el de la humildad, la gratitud y el recuerdo de los donadores ante Dios, frecuentemente realizada a través de la oración o de la asistencia a los sufragios en su memoria ${ }^{11}$.

Las limosnas concedidas a los pobres podían ser de diverso tipo: en dinero, en géneros, en ropa o en pago por servicios realizados.

Pero practicar la caridad era también recibir a los pobres errantes en sus casas, proporcionándoles cobijo y reposo por una o más noches, o erigir una institución que se dedicase a ofrecer tales servicios. En la Edad Media, los albergues y hospitales recogían pobres que se encontraban en tránsito, ofreciéndoles la posibilidad de cobijarse en ellos durante algunas noches -normalmente esa gracia nunca excedía de las tres- para que pudiesen descansar y proseguir su viaje ${ }^{12}$. Fue también en este período cuando comenzarán a nacer los hospitales para peregrinos, centros especialmente dedicados a auxiliar a las personas en tránsito. Estos hospitales estaban normalmente ubicados junto a las principales vías de comunicación y facilitaban la llegada y la partida a los que lo solicitaban ${ }^{13}$. La

${ }^{9}$ Con ocasión de la muerte del rey Juan V, el arzobispo de Braga, D. José de Braganza, su hermano ilegítimo, mando distribuir limosna a los pobres a la puerta de su palacio arzobispal. Vid. Milheiro, M. M. (2003). Braga. A cidade e a festa no século XVIII. Viseu: NEPS, pp. 243-244.

${ }^{10}$ Sobre la acción caritativa de este duque consúltese: LoBo DE ARAúJo, M. M. (2004). "Vila Viçosa, os pobres e as esmolas do duque D. João II (1636-1646)". Revista de Demografía Histórica, pp. 183-205.

${ }^{11}$ Lobo De Araújo, M. M. (2000). Dar aos pobres e emprestar a Deus: as Misericórdias de Vila Viçosa e Ponte de Lima (séculos XVI-XVIII). Barcelos: Santa Casa da Misericórdia de Vila Viçosa; Santa Casa da Misericórdia de Ponte de Lima, pp. 244-245.

12 A propósito de estas instituciones Vid. DA Silva CorreIA, F. (1943). "Hospitais medievais portugueses". A Medicina Contemporânea", 11-15.

${ }^{13}$ Ferreira De Almeida, C. A. (1973). "Os caminhos e a assistência no Norte de Portugal”. En Primeiras Jornadas Luso-Espanholas de História Medieval - A pobreza e a assistência aos pobres na Península Ibérica durante a Idade Média: Actas. T. 1. Lisboa: Instituto da Alta Cultura, pp. 40-47. 
localización de estas instituciones se enfoca desde la concepción que otorga al pobre medieval un carácter itinerante, lo que explica su situación en los principales caminos. Su creación posibilitó el auxilio a los viajeros en un espacio apropiado, apartándolos de la familiaridad del hogar.

Las peregrinaciones fueron en la Edad Media responsables de un constante trajín de personas en dirección a los santuarios de su devoción. Escogidas por muchos como medio para agradecer o solicitar gracias al cielo, las peregrinaciones lanzaban a un elevado número de gentes a las carreteras que las comunicaban con los centros religiosos de mayor prestigio. De esta manera las principales vías se llenaban de devotos errantes. De los tres grandes centros de peregrinación Jerusalén, Santiago de Compostela y Roma- Compostela era, probablemente, la más popular ${ }^{14}$, mas, aún así, todos asistían a la llegada de romeros, ya fueran procedentes de los grupos sociales más humildes, de los sectores más poderosos o incluso reyes y reinas.

En la Edad Moderna, ya sin la pujanza que habían conocido en el período anterior, las peregrinaciones continuaban sirviendo de pretexto para que, de manera individual o en grupo, los hombres abandonasen sus casas para ir al encuentro del santuario de su devoción ${ }^{15}$. Otros, se veían obligados a desplazarse por causa de sus dolencias; cuando no se podían tratar en su tierra, tenían que buscar la cura en lugares más alejados. Junto a las razones religiosas o médicas, otros se desplazaban por distintos motivos, asociados a cuestiones personales, familiares o incluso profesionales. Cuando iban a cumplir condena, estos pobres eran igualmente portadores de cartas de guía, que renovaban en las Misericordias por donde pasaban.

Con la reforma de la asistencia y con el nacimiento de las Misericordias en Portugal -la de Lisboa, fue creada en 1498-, muchos establecimientos de caridad que se hallaban sumidos en una profunda crisis fueron incorporados a ellas. Estas cofradías, que reunían en sí la práctica de las 14 obras de caridad, tuvieron un desempeño fundamental en el campo de la asistencia a lo largo de la Edad

${ }^{14}$ Wade Labarge, M. (1992). Viajeros medievais. Los ricos y los insatisfechos. Madrid: NerEA, p. 130.

15 Sobre las peregrinaciones y los santuarios de gran devoción Vid. DA Silva PinTo CorReia Pereira, M. H. (1961). Subsídios para o estudo da assistência no Norte de Portugal. Coimbra: Faculdade de Letras, p. 15, (dis. de licenciatura en Ciências Históricas e Filosóficas). Para las procesiones en torno al santuario de "Nossa Senhora da Nazaré" Vid. Penteado, P. (1998). Peregrinos da memória: o santuário de Nossa Senhora da Nazaré 1600-1785. Lisboa: Universidade Católica Portuguesa; Centro de Estudos de História Religiosa, pp. 97-115. 
Moderna. Debemos subrayar su destacado papel en el mundo urbano, donde alcanzará un lugar de relieve en el combate contra la pobreza.

Los estudios más recientes sobre las Misericordias han destacado el carácter articulado de su acción en la asistencia a la pobreza, así como su desempeño en ámbitos locales. Algunos otros trabajos, igualmente recientes, llaman la atención sobre la función asistencial de los obispos ${ }^{16}$, cabildos catedralicios ${ }^{17}$, otras cofradías ${ }^{18} \mathrm{o}$ incluso de los señores locales.

\section{LAS CARTAS DE GUÍA}

En este trabajo nos dedicaremos a analizar el desempeño de las Misericordias en la ayuda a los viajeros, es decir, a aquellos que se hallaban en tránsito, enfermos o no, pero que necesitaban de auxilio. Estudiaremos las cartas de guía durante los siglos XVII al XIX y analizaremos los grupos beneficiados por estas cofradías y los motivos que justificaban las ayudas otorgadas.

Aunque no constituía una obra de misericordia, el reparto de cartas de guía estaba instituido en las constituciones de las Misericordias, constituyéndose en documentos fundamentales de auxilio a los pobres ${ }^{19}$. Se incluían dentro de las acciones asistenciales que desarrollaban estas cofradías y se convirtieron en un servicio muy demandado.

Una carta guía era un documento entregado por un benefactor o una institución a una persona individual o a un agregado familiar, en el que se identificaba a sus portadores, su procedencia geográfica y el lugar de destino. Asimismo, explicaba las razones del viaje y funcionaba como salvoconducto que, una vez entregado a otra institución, permitía acceder a los servicios de caridad. Los portadores de las

16 PaIVA, J. P. (2002). "D. Frei Luís da Silva e a gestão dos bens de uma mitra”. Estudos de Homenagem a João Francisco Marques. Oporto: Faculdade de Letras da Universidade do Porto, pp. 252-255.

${ }^{17}$ En lo que atañe a la acción asistencial del cabildo de Braga. Vid. Dinis, C. y BARBosA, F. (2003). "Pobreza e caridade: a acção assistencial do cabido bracarense em período de Sé Vacante (1728-1741)". Cadernos do Noroeste. 1-2, pp. 497-522.

${ }^{18}$ Lobo De ARAúJo, M. M. (2001-2002) "A ajuda aos pobres nas confrarias de Nossa Senhora da Guia e do Espírito Santo de Ponte de Lima (séculos XVII- XIX)”. Revista Cultural Bracara Augusta. pp. 441-443.

19 Archivo de la "Santa Casa da Misericórdia" de Ponte de Lima (a partir de ahora ASCMPL), Compromisso de 1618. Capítulos Reformados de 1631, p. 48v.; Archivo Distrital de Braga, Compromisso da Misericórdia da cidade de Braga, Braga, Francisco Fernandez de Basto, 1631, p. 16; Compromisso da Misericórdia de Lisboa, Lisboa, Pedro Gaesbeeck, 1619, p. 31. 
cartas guías estaban seguros de que recibirían auxilio. Este hecho, explica su importante demanda en las instituciones asistenciales.

Las cartas de guías se destinaban a los pobres que se hallaban en tránsito o necesitaban efectuar un viaje y garantizaban la asistencia hasta la institución asistencia hacia donde se desplazaban o hasta su propia casa. Así, configurándose una verdadera cadena de solidaridad, las instituciones caritativas garantizaban que los pobres lograsen proseguir su viaje de forma asistida, llevando frecuentemente hasta sus propias moradas o a cualquier otro lugar al que se propusieran llegar. Los beneficiarios de esta ayuda se desplazaban de Misericordia en Misericordia, renovando estos "pasaportes" de caridad.

La Santa Casa de Ponte de Lima concibió desde siempre la expedición de estos documentos como un eficaz mecanismo de ayuda a los pobres, gastando semanalmente varias decenas de reales en esta forma de caridad ${ }^{20}$.

La mayor parte de las cartas de guías emitidas por la cofradía de Ponte de Lima en la primera mitad del siglo XIX, se destinaron de manera individual a hombres y mujeres. Aún así existen también ejemplos de auxilio a familias que se hallaban en tránsito y necesitaban ayuda. El auxilio prestado por la Santa Casa podía manifestarse de diferentes modos: podía ser en dinero o conjugando éste con el transporte. La cofradía podía conformarse con la entrega de una cantidad monetaria o agregar a ésta una cabalgadura y un hombre para transportar al pobre a la Misericordia más próxima, donde nuevamente solicitaba auxilio y se renovaba la carta de guía, y así sucesivamente hasta llegar al lugar de destino. La limosna se acompañaba siempre de un documento, la carta guía, que atestiguaba la pobreza del individuo. Las cartas de guía eran, por lo tanto, documentos fundamentales, verdaderos "pasaportes" de caridad, atribuidos a quien por varias razones, tenía necesidad de desplazarse y no disponía de los medios suficientes como para hacerlo con las debidas condiciones.

Un documento regio de 1 de diciembre de 1690, determinaba que solamente la Misericordia de Lisboa tenía poderes para "mandar imprimir e distribuir cartas de guía pelas outras irmandades do reino" ${ }^{21}$, centralizando así estos servicios en la Misericordia de la capital. Ésta non tenía ningún tipo de poder sobre sus restantes

${ }^{20}$ El registro de los gastos de la institución se efectuaba en los días de cabildo (domingo y miércoles). Dicha información nos permite analizar este tipo de actividades. ASCMPL, Livros de receita e despeza.

${ }^{21}$ Serrão, J. V. (1998). A Misericórdia de Lisboa. Quinhentos Anos de História. Lisboa: Livros Horizonte, p. 168. 
hermanas, pero el modelo de creación de estas cofradías y su propio funcionamiento llevaba a muchas de ellas a denominar expresamente a la de Lisboa como "casa mãe". Las Misericordias recibían en el momento de su fundación los estatutos de la de Lisboa, si bien podían alterarlo o crear uno nuevo, como aconteció en algunos casos, en los que solicitaban a los monarcas los privilegios otorgados a la lisboeta. De todos modos, esta cofradía, era considerada por muchas de las restantes como la casa matriz y el modelo a seguir. Se trataba de un poder simbólico y en ocasiones, un tanto difuso, como en lo tocante a la expedición de cartas guías.

Como ya hemos indicado, todas las Misericordias se implicaron en este tipo de auxilio a la pobreza. Las razones esgrimidas para la concesión de limosnas eran muy variadas. En 1562, la Misericordia de Monção registraba en sus libros una ayuda de 30 reales que la institución concedía a una mujer pobre que portaba una carta guía de la Misericordia de Ponte de Lima. La mujer se había desplazado desde aquella localidad con el fin de solucionar ciertos asuntos con un pobre que se hallaba preso $^{22}$. Ese mismo año, la misma Misericordia concedía a Maria Álvares un auxilio de 200 reales para ayudarla a alquilar una bestia con la que poder viajar hasta el lejano hospital de Santiago ${ }^{23}$. Se trataba, ciertamente, de una ayuda de gran trascendencia para la pobre, dado que la localidad de Monção no disponía de hospital.

En aquella localidad solamente existía la leprosería de São Gião ${ }^{24}$, concedida por D. Sebastián a la Misericordia de la villa el año anterior, sin haber en todo el término municipal ninguna otra unidad para cuidados de la salud. En los casos más graves, que exigían inevitablemente el internamiento en un centro, los enfermos se veían obligados a desplazarse desde su lugar de origen hacia otras localidades en donde pudieran recibir mejores cuidados. La opción de Santiago de Compostela era una posibilidad que les obligaba a cruzar la frontera y buscar en España unos servicios de salud con los que no contaban en su tierra.

La ayuda que englobaba una bestia y un hombre para conducirla se destinaba fundamentalmente a los enfermos. El animal era normalmente alquilado para tal efecto. En él iba montado el pobre que se hallaba padeciendo su enfermedad y, por lo tanto, incapaz de caminar. Cuando el pobre llegaba sobre una cabalgadura a una

\footnotetext{
22 Archivo de la Santa Casa da Misericordia de Monção (a partir de ahora, ASCMM), Livro de receita e despeza 1561-1612, $\mathrm{n}^{\circ} 16, \mathrm{fl} .17 \mathrm{v}$.

${ }^{23}$ ASCMM, Livro de receita e despeza..., $\mathrm{n}^{\mathrm{o}}$ 16, fl. 18.

${ }^{24}$ Este centro asistencia se hallaba fuera de la villa, aunque en un emplazamiento próximo a ella.
} 
Misericordia, generalmente, se le proveía con otra, ya que resultaba absolutamente necesario aliviar, en la medida de las posibilidades, las dificultades del viaje.

En Marzo de 1564, la Misericordia de Monção, pagó 60 reales a un hombre que llevó a un enfermo desde aquella localidad hasta Valença y en 1795, se ordenaban entregar 240 reales a "um pobre vindo com cabalgadura da misericordia de Lamego para o reyno da Galiza" 25 .

También la Misericordia de Montemor-o-Velho facilitaba el desplazamiento de enfermos a través de las cartas de guía. En este caso el lugar de destino en donde beneficiarse del tratamiento médico era la ciudad de Coimbra ${ }^{26}$.

Aunque generalmente el desplazamiento de viajeros y peregrinos se solía efectuar bien mediante una cabalgadura o bien mediante un carro empujado por animales, a veces estos medios de transporte eran sustituidos por otros medios de desplazamiento. La Misericordia de Aveiro enviaba a sus pobres con carta de guía en dirección a Ovar en el barco de su propiedad o, en su defecto, en los que transportaban la sal ${ }^{27}$.

La Misericordia de Mora tenía una gran tradición en este campo. El servicio era pregonado por el portero de la Cámara. Quien estuviese interesado en "meter os pobres de caminho", se personaba en la subasta y a aquel que cobraba menos por dicho trabajo se le adjudicaba ${ }^{28}$. El resultado era anunciado en la Santa Casa por el ya referido "oficial camarário", que era el que nombraba al vencedor. Entonces, la cofradía establecía con aquel hombre el pertinente contrato, ostentando la prestación de este servicio por el espacio de un año.

No siempre las Misericordias han preservado la documentación que posibilita conocer y estudiar a los beneficiados de sus limosnas. De hecho, lo más común es que las fuentes se refieran casi exclusivamente al montante de los gastos, sin dejar rastro de las peticiones que llegaban a ellas. Sin embargo, en el siglo XIX, la

25 ASCMM, Livro que ha de servir dos acordons desta Santa Mizericordia da villa de Monçõn 1774-1815, nº 12, fl. 125.

${ }^{26}$ Para la Misericordia de Montemor-o-Velho véase, Costa DA SiLva, M. J. (1999). A Santa Casa da Misericórdia de Montemor-o-Velho. Espaço de sociabilidade, poder e conflito (1546-1803). Figueira da Foz: Câmara Municipal de Montemor-o-velho, pp. 84-85.

${ }^{27}$ Sobre el desplazamiento de los pobres en la Misericordia Aveiro Vid. BARREIRA, M. (1998). Santa Casa da Misericórdia de Aveiro. Poder, pobreza e solidariedade. Águeda: Santa Casa da Misericórdia de Aveiro, p. 147.

${ }^{28}$ Archivo de la "Santa Casa da Misericórdia de Mora", Livro de actas 1639-1648, fl. 10. 
Misericordia de Ponte de Lima plasmó en su documentación con meridiana claridad quiénes eran los beneficiados de aquellas ayudas, especificando, además, su lugar de naturaleza y el destino hacia donde se dirigían.

En 1815 era tramitada una carta de guía para João Ventura, soldado que era del regimiento de infantería número 21. Este hombre era natural de Touvedo, feligresía del concejo de Ponte da Barca e iba "em dereitura para a cidade de Lisboa". La razón de su desplazamiento no fue mencionada en el registro. La inscripción de soldados en las listas de beneficiados era frecuente tras el fin de conflictos bélicos, momento en el que estos militares sin ocupación, se veían obligados a regresar a sus hogares. Sin posesiones de valor, con frecuencia, enfermos o mutilados por los efectos de la guerra, los soldados pobres encontraban auxilio en las Misericordias, sobre todo en aquellas situadas en zonas fronterizas.

Igualmente, desconocemos los motivos que llevaron a la familia García a pedir ayuda a la Santa Casa de Ponte de Lima. Manuel Caetano García, su mujer, Manuela Fernandes, y su hijo llamaron a la puerta de aquella Misericordia en 1816. Eran naturales de Goam, en el reino de Galicia, y se hallaban de camino hacia la "cidade de Bragança e de como erão os mesmos apresentarão Pasaporte do juiz de Fora de Villa Nova de Cerveira" ${ }^{29}$. Este ejemplo, muestra a las claras cómo la caridad de las Misericordias, en este caso la de Ponte de Lima, se extendía allende las fronteras: esta familia de gallegos obtuvieron también, como los portugueses, su tan deseada carta de guía.

Si bien la ayuda colectiva a las familias no fue muy frecuente, por lo menos en lo que atañe a esta Misericordia, hemos podido verificar algunos ejemplos de este tipo en la documentación consultada. Cuando los pobres se desplazaban con todo su agregado familiar, esta circunstancia constituía un argumento más para obtener la ayuda necesaria de la Misericordia. También, en 1818, Mariana Casimira y dos de sus hijos se beneficiaron de este tipo de limosna. Venían de la ciudad de Lisboa y se hallaban de camino hacia Santiago de Compostela ${ }^{30}$. Los motivos que habían llevado a esta mujer a partir de la capital portuguesa con dos hijos, probablemente aún pequeños, no eran mencionados. Aún así, y atendiendo al lugar de destino, parece lógico pensar que estamos ante razones de corte religioso ${ }^{31}$.

\footnotetext{
${ }^{29}$ ASCMPL, Livro do copiador, $\mathrm{n}^{\circ}$ 27. (Deteriorado en el lugar de la paginación).

${ }^{30}$ ASCMPL, Livro do copiador $\mathrm{n}^{\mathrm{o}} 27$.

${ }^{31}$ Sobre las peregrinaciones hacia Santiago de Compostela Vid. ABReU, A. A. (1993). Caminhos de Santiago no Entre Douro e Minho. Viana do Castelo, pp. 26-30.
} 
Ese mismo año, la Santa Casa de Ponte de Lima, otorgó una carta de guía a Maria Benta, soltera, que venía desde Valença hacia el hospital de San Marcos de Braga. Por su parte, António José Mendonça, procedente de la ciudad de Oporto, obtuvo una carta de guía para Bilbao, en España. Otro español, Manuel Dias, soltero y natural de Lugo (Galicia), conseguía también la suya, con el objetivo de llegar a Monção, donde quería tomar los baños. También João Fernandes, soltero y natural da Feitosa (concejo de Ponte de Lima), se dirigía a aquella localidad famosa por sus baños termales con el mismo fin. Obviamente, en estos dos últimos casos, al tratarse de un tratamiento especializado, que solamente se podía recibir en aquellos lugares que reuniesen las condiciones necesarias, todos los que lo demandaban, estaban obligados a desplazarse.

\begin{tabular}{lll}
\hline \multicolumn{1}{c}{ Cuadro 1. Cartas de guía pasadas por la Misericordia de Ponte de Lima em 1817} \\
$\begin{array}{l}\text { Nombres de los } \\
\text { beneficiados }\end{array}$ & \multicolumn{1}{c}{ Procedencia } & \multicolumn{1}{c}{ Direcciones tomadas } \\
\hline $\begin{array}{l}\text { Simão Bugalho, } \\
\text { gallego }\end{array}$ & $\begin{array}{l}\text { Venía de la ciudad de Braga con } \\
\text { carta de guía. }\end{array}$ & $\begin{array}{l}\text { "Em dereitura a Santiago de } \\
\text { Galiza." }\end{array}$ \\
$\begin{array}{l}\text { Guilherme } \\
\text { gallego }\end{array}$ & $\begin{array}{l}\text { De la feligresía de "Santo Orense"en } \\
\text { el Arzobispado de Santiago } \\
\text { (Galicia). }\end{array}$ & $\begin{array}{l}\text { "Em dereitura à Mizericordia } \\
\text { de Vallença, com } \\
\text { cavalgadura". }\end{array}$ \\
\hline $\begin{array}{l}\text { Luisa Rosa, } \\
\text { viuda }\end{array}$ & $\begin{array}{l}\text { De la feligresía de Viade, Concello } \\
\text { de Basto. }\end{array}$ & $\begin{array}{l}\text { "Em dereitura à cidade de } \\
\text { Braga e dahi a sua patria, com } \\
\text { cavalgadura". }\end{array}$ \\
\hline António Fulio & $\begin{array}{l}\text { Con carta de guia de la Misericordia } \\
\text { de la ciudad de "Gran Porto de Santa }\end{array}$ & $\begin{array}{l}\text { "Em dereitura a Santiago de } \\
\text { Galiza." }\end{array}$ \\
\hline $\begin{array}{l}\text { Mrancisco José } \\
\text { de Sousa }\end{array}$ & $\begin{array}{l}\text { Con carta de guia de la Misericordia } \\
\text { de la ciudad de Lamego. }\end{array}$ & $\begin{array}{l}\text { "Em dereitura a Vallença do } \\
\text { Minho." }\end{array}$ \\
\hline $\begin{array}{l}\text { João António } \\
\text { Ramos }\end{array}$ & $\begin{array}{l}\text { Con carta de guia de la Misericordia } \\
\text { de Braga. }\end{array}$ & $\begin{array}{l}\text { "Em dereitura a Vallença do } \\
\text { Minho." }\end{array}$ \\
\hline Luís Cambão & $\begin{array}{l}\text { Del reino de Galicia, con carta de } \\
\text { guia de la Misericordia de Braga. }\end{array}$ & $\begin{array}{l}\text { "Em dereitura à Mizericordia } \\
\text { de Vallença do Minho." }\end{array}$ \\
\hline $\begin{array}{l}\text { António } \\
\text { Joaquim, soltero }\end{array}$ & $\begin{array}{l}\text { De la feligresía de Santa Comba, } \\
\text { Couto de Bertiandos. }\end{array}$ & $\begin{array}{l}\text { "Em dereitura à cidade de } \\
\text { Lisboa." }\end{array}$ \\
\hline $\begin{array}{l}\text { Joaquim } \\
\text { Rodrigues }\end{array}$ & $\begin{array}{l}\text { De Valencia, Reino de España, con } \\
\text { carta de guia de Alcacer do Sal. }\end{array}$ & $\begin{array}{l}\text { "Em dereitura a Santiago de } \\
\text { Galiza." }\end{array}$ \\
\hline Manuel Dias & $\begin{array}{l}\text { Del Reino de Galicia, obispado de } \\
\text { Lugo. }\end{array}$ & $\begin{array}{l}\text { "Em dereitura à cidade do } \\
\text { Porto." }\end{array}$ \\
\hline Cipriano Rinon & $\begin{array}{l}\text { Con carta de guia de la Misericordia } \\
\text { de la ciudad de Lisboa. }\end{array}$ & $\begin{array}{l}\text { "Em dereitura para o Reino de } \\
\text { Galiza." }\end{array}$ \\
\hline
\end{tabular}




\begin{tabular}{|c|c|c|}
\hline $\begin{array}{l}\text { Romão Cauze, } \\
\text { mujer Maria } \\
\text { Fernandes e hijo } \\
\text { Matheos }\end{array}$ & De villa de Neda, Reino de Galicia. & $\begin{array}{l}\text { "Em dereitura à cidade de } \\
\text { Lisboa." }\end{array}$ \\
\hline $\begin{array}{l}\text { João Baptista } \\
\text { Megeceim }\end{array}$ & $\begin{array}{l}\text { De nación genovés, con carta de guia } \\
\text { de la Misericordia de Coimbra. }\end{array}$ & $\begin{array}{l}\text { "Em dereitura a Vallença do } \\
\text { Minho." }\end{array}$ \\
\hline João Ihoá & $\begin{array}{l}\text { Con carta de guia de la Misericordia } \\
\text { de la ciudad de Coimbra. }\end{array}$ & $\begin{array}{l}\text { "Em dereitura a Vallença do } \\
\text { Minho." }\end{array}$ \\
\hline Manuel Correia & $\begin{array}{l}\text { De Carrelan, comarca de Villa Real, } \\
\text { con carta de guia de aquella villa. }\end{array}$ & "Em dereitura a Villa Real." \\
\hline $\begin{array}{l}\text { José Bento } \\
\text { Marinho }\end{array}$ & $\begin{array}{l}\text { De la provincia de Santiago en } \\
\text { Galicia, con carta de guia de la } \\
\text { Misericordia de Viana.. }\end{array}$ & $\begin{array}{l}\text { “Em dereitura à Praça de } \\
\text { Vallença do Minho com a } \\
\text { esmola do custume." }\end{array}$ \\
\hline $\begin{array}{l}\text { Maria Thomasia } \\
\text { Gonsalves }\end{array}$ & $\begin{array}{l}\text { Del reino de Galicia, con carta de } \\
\text { guia de la Misericoridia y el Hospital } \\
\text { de San Marcos de la ciudad de } \\
\text { Braga. }\end{array}$ & $\begin{array}{l}\text { "Em dereitura a sua pátria, } \\
\text { com esmola do custume." }\end{array}$ \\
\hline $\begin{array}{l}\text { José Coelho de } \\
\text { Figueiredo }\end{array}$ & $\begin{array}{l}\text { De Valença do Minho con carta de } \\
\text { guia de aquella localidad y } \\
\text { cabalgadura. }\end{array}$ & $\begin{array}{l}\text { "Em dereitura ao Hospital de } \\
\text { São Marcos, da cidade de } \\
\text { Braga, com esmola e } \\
\text { cavalgadura." }\end{array}$ \\
\hline Manuel José & $\begin{array}{l}\text { De San Julián, en el obispado de Tui, } \\
\text { Reino de Galicia, con carta de guia } \\
\text { de la Misericordia de Vallença. }\end{array}$ & $\begin{array}{l}\text { "Em dereitura para a cidade } \\
\text { do Porto, com esmola } \\
\text { custumada e cavalgadura." }\end{array}$ \\
\hline $\begin{array}{l}\text { João Baptista, } \\
\text { soltero }\end{array}$ & $\begin{array}{l}\text { De la feligresía de Rio Calvo, } \\
\text { "Terras de Bouro". }\end{array}$ & $\begin{array}{l}\text { "Em dereitura à sua pátria } \\
\text { com esmola do custume." }\end{array}$ \\
\hline $\begin{array}{l}\text { Ignacio } \\
\text { Tremonte y su } \\
\text { mujer Manuella } \\
\text { Alves }\end{array}$ & $\begin{array}{l}\text { De Santiago de Galicia,con carta de } \\
\text { guia de la Misericordia de la ciudad } \\
\text { de Braga. }\end{array}$ & $\begin{array}{l}\text { "Em dereitura à sua pátria } \\
\text { com esmola do custume." }\end{array}$ \\
\hline José António & $\begin{array}{l}\text { De Valença do Minho, con carta de } \\
\text { guia de la ciudad de A Goarda y } \\
\text { cavalgadura. }\end{array}$ & $\begin{array}{l}\text { "Em dereitura a sua pátria, } \\
\text { com esmola do custume e } \\
\text { cavalgadura." }\end{array}$ \\
\hline José Lourenço & $\begin{array}{l}\text { De Carrezedo, comarca de Chaves, } \\
\text { pidiendo con una imagen de Santa } \\
\text { Bárbara da Veiga de Sila. }\end{array}$ & $\begin{array}{l}\text { "Em dereitura a Santiaho de } \\
\text { Galiza com esmola } \\
\text { custumada." }\end{array}$ \\
\hline Manuel Bento & $\begin{array}{l}\text { De Barcellos,con carta de guia de la } \\
\text { Misericordia de Vallença do Minho } \\
\text { y cavalgadura. }\end{array}$ & $\begin{array}{l}\text { "Em dereitura a Barcellos, } \\
\text { com esmola do custume e } \\
\text { cavalgadura." }\end{array}$ \\
\hline
\end{tabular}

FUENTE: ASCMPL, Livro do copiador, $\mathrm{n}^{\circ}$ 27, deteriorado en el lugar de la paginación.

El análisis del cuadro $n^{\circ} 1$, nos permite verificar el movimiento de circulación de las gentes en torno a la Misericordia, así como la adecuación de la limosna a 
cada situación particular. La posición geográfica de Ponte de Lima explica su transformación en un auténtico corredor. Por él se desplazaban todas aquellas personas que desde Portugal se dirigían a España, fundamentalmente a Galicia y muy particularmente a Santiago de Compostela. El caso de José Lourenço es un fiel testimonio de lo que acabamos de afirmar. Este peregrino de Chaves iba de camino hacia Compostela, presumiblemente para cumplir una promesa. A lo largo de ese periplo, iba pidiendo limosna por donde pasaba con una imagen de Santa Bárbara, y fue de esta manera como llegó a la Misericordia de Ponte de Lima. De hecho, por todo el Alto Miño, se desplazaba un nutrido contingente de personas que se desplazaban hacia Compostela. Ponte de Lima auxilió a muchos de estos caminantes que, tanto por tierra como por mar, llegaban a la villa en busca de ayuda para poder proseguir su viaje. La Misericordia de la localidad, a través de las cartas de guías o de otro tipo de limosnas, favorecía a los romeros ${ }^{32}$.

Por otro lado, desde el siglo XVIII, Portugal se convirtió en un importante polo de atracción para los gallegos, que atravesaban la frontera en busca de trabajo ${ }^{33}$. Su presencia en el Miño está abundantemente constatada, tanto para aquella centuria como para la siguiente. Muchos de estos inmigrantes terminaban por pedir limosna en la Santa Casa de Ponte de Lima. En ella solicitaban cartas de guía con el objeto de encaminarse hacia Valença o Monção, donde renovaban el documento para después dirigirse a su lugar de origen.

Junto a este movimiento de gallegos pobres, que no lograrían desplazarse sin la ayuda de las Misericordias, existían otros menesterosos necesitados de limosna para regresar a sus casas y otros que se dirigían a hospitales, mayoritariamente al de San Marcos de Braga. Buscaban así tratamiento para sus males. Probablemente, eran portadores de enfermedades contagiosas, como la sífilis, tratadas exclusivamente en algunos centros especializados. Normalmente, los centros asistenciales de pequeñas dimensiones, como el de Ponte de Lima, no podía ofrecer ese tipo de tratamientos, al no disponer de las condiciones logísticas para poder ponerlos en práctica ${ }^{34}$. Sin embargo, el hospital de San Marcos administraba curas

32 Fernandes Moreira, M. A. (1993). “A Misericórdia de Viana na rota dos peregrinos de Santiago". Estudos Regionais. 13-14. pp. 66-72.

33 Sobre la presencia de inmigrantes gallegos que llegaban en busca de trabajo, Vid. SouSA DE CAstro, (1947). "Trechos escolhidos. O braço galego na epopeia de Riba Douro". Cadernos Mensais de Estatística. Abril, p. 166; De Oliveira, A. (1995). "Migrações internas e de média distância em Portugal 1500-1900". Arquipélago. História, $2^{\mathrm{a}}$ série, p. 280.

${ }^{34}$ Para poder realizar el tratamiento de la enfermedad era preciso que el hospital reuniese las condiciones logísticas necesarias, que posibilitasen una adecuada separación de estos pacientes con respecto a los demás, así como de toda la ropa empleada en estas curas. Cuando no se realizaban en 
para ese mal dos veces al año ${ }^{35}$. Los que no se dirigían a aquel centro optaban por encaminarse a localidades más alejadas, caso de Lisboa, Oporto o Vila Real.

Los desplazamientos hacia hospitales que ofertaban tratamiento frente al mal gálico han quedado también reflejados en la documentación de la Misericordia de Coimbra, lugar de paso para un considerable número de enfermos que iban de camino hacia los lugares en donde se efectuaban esos tratamientos ${ }^{36}$.

Hasta el mes de mayo de 1818, la Santa Casa de Ponte de Lima había firmado un total de trece cartas de guía. Este número parece hallarse en sintonía con lo observado para el año anterior, en el que se firmaron veinticuatro para sus doce meses y se presume muy inferior al nivel de acción de la Misericordia en los siglos XVII e XVIII. La pista para sustentar esta presunción la hallamos en la propia documentación de aquella institución; si bien es cierto que para aquellos dos siglos no poseemos en el archivo de la Misericordia información directa que nos muestre el número de cartas de guía firmadas al mes o al año, contamos con los datos aportados por los registros bisemanales en donde se reflejaba el monto económico de aquellas ayudas. Esa información indirecta constata que el número de cartas de guía era muy superior en los siglos XVII y XVIII que en el XIX.

De los trece casos hallados para 1818, cinco -es decir, el 38,4\%- eran cartas destinadas a individuos que se desplazaban al hospital de San Marcos de Braga, contando el $61,5 \%$ de ellos con cabalgadura proporcionada por la institución.

El caso de José Vidal resulta un tanto enigmático. Este pobre natural de Melgaço, pasó por Ponte de Lima cuando regresaba a su tierra desde la ciudad de Lisboa, donde había estado tomando "ares Patrios". Esa difusa razón esgrimida no nos permite comprender con exactitud las razones de aquel desplazamiento, aunque no nos cabe la menor duda de que se hallaba enfermo. Como los demás pobres, José fue proveído de la limosna acostumbrada, junto a una cabalgadura ${ }^{37}$.

Los pobres que se hallaban imposibilitados de proseguir su camino y necesitaban pernoctar en Ponte de Lima contaban con el auxilio del "Hospital de

\footnotetext{
hospitales especializados, se procuraba también separar a estos pacientes para evitar la comunicación con los restantes.

35 Sobre el tratamiento del mal gálico en el hospital de S. Marcos de Braga Vid. CASTRO, M. F. (1993). "A assistência no Hospital de S. Marcos da $2^{a}$ metade do século XVII a cerca de 1710". Revista Cultural Bracara Augusta. 44, pp. 45-73.

${ }^{36}$ LOPES, M. A. Pobreza, assistência e controlo social..., p. 88.

${ }^{37}$ ASCMPL, Livro do copiador, $\mathrm{n}^{\mathrm{o}} 27$.
} 
Fora" ${ }^{38}$, institución de origen medieval creada para dar albergue a los peregrinos. En 1834, este hospital continuaba recogiendo "por hum a três dias os mendigos que transitavam nesta villa [mas] também nelle se recolhem e sustentão alguns daqueles pobres que entrevados nada esperão neste mundo mais do que a morte" ${ }^{\text {"39 }}$.

Pese a su significado y al papel de relevancia que desempeñaban en el mundo de la asistencia a la pobreza, las cartas de guía fueron objeto de importantes críticas en el siglo XIX. La administración del concejo de Ponte de Lima envió una carta a la Misericordia de la villa en 1853 en la que se le informaba del reglamento vigente de policía. En él se prohibía a cualquier persona, incluidos los mendigos, transitar sin pasaporte. Como la circulación de pobres estaba patrocinada por las Misericordias, era especialmente importante que respetasen ese requisito. Los pobres pues, junto a las cartas de guía debían de contar con los pasaportes expedidos por las autoridades políticas. Este documento identificador, bastante común en la Europa del momento ${ }^{40}$, ofrecía una información más completa, que posibilitaba un conocimiento más profundo de su portador. Para su generalización se invocaban razones vinculadas a la seguridad por los caminos, sobre todo frente a los considerados peligrosos, como los vagabundos. Generalmente, la persona se registraba, describiéndose sus señales físicas particulares, fundamentalmente del rostro $^{41}$. Estos elementos identificadores resultaban de especial relevancia para conocer al viajero.

De esto modo consideraban las autoridades civiles de Ponte de Lima que "sendo certo que transitão por todo o Reino com cartas de guia das Mizericordias homens que pudendo empregar-se em alguns ramos de trabalho, impetrão as mesmas guias, fingindo ser doentes e assim vão roubando de terra em terra e comethendo outros crimes para ebitar aos quaes em cumprimento do que é ordenado pelo Governo Civil deste distrito [...] Vossa Senhoria [o provedor] não confira mais guias a pessoas alguãs que lhe não apresentem o competente passaporte" ${ }^{\text {"2 }}$.

38 Esta denominación se relacionaba con el hecho de que el hospital se hallaba fuera de las murallas de la villa.

${ }^{39}$ ASCMPL, Livro do copiador, $\mathrm{n}^{\mathbf{0}} 27$, fl. 100.

${ }^{40}$ Para el caso francés. Vid. TORPEY, J. (2002). The invention of the passport. Surveillance, Citizenship and the State. Cambridge: Cambridge University Press, pp. 21-30.

${ }^{41}$ Sobre la descripción de los pasaportes Vid. CAPLAN, J. y TORPY, J. (Ed.). (2001). Documenting Individual Identity. The development of state practices in the modern world. Princeton y Oxford: Princeton University Press, pp. 25-26.

${ }^{42}$ ASCMPL, Livro do copiador $\mathrm{n}^{\circ} 27$, (no paginado). 
Este tipo de medidas no eran, ni mucho menos, novedosas. Ya en el lejano 1771 la Cámara había determinado la obligatoriedad del uso de los pasaporte, tanto para aquellos forasteros que llegaban a la villa como para los naturales que deseasen $\operatorname{partir}^{43}$.

La respuesta de la Santa Casa no se hizo esperar. El proveedor afirmó tajantemente que la cofradía de la villa no pasaba "nenhuãs cartas de guia [...] a mendigos pobres que cem passaporte transitem pelas terras do Reino antes com bastante admiração tem olhado para a facilidade com que muitas outras franqueão taes documentos a vagabundos, que a titulo de mendigarem hua esmola percorrem vijiando diversos destritos e muitas vezes é verdade com prejuizo dos povos". Después de atestiguar su conformidad con la política aplicada en aquellos momentos y de defender la acción social de la Misericordia de Ponte de Lima, el proveedor denunciaba las prácticas de la Misericordia de Viana do Castelo que, según él, continuaba expidiendo documentos sin ningún tipo de control, favoreciendo "a apresentação de peregrinos com cartas de guia [na sua Misericórdia] a exigir a esmola ordinaria que lhes confere o nosso compromisso". Finalmente, recordaba a las autoridades civiles, que las cartas de guías firmadas por la Misericordia de Ponte de Lima eran entregadas casi exclusivamente a aquellos enfermos del municipio que, por razón de su enfermedad, no podían recibir asistencia en el hospital de la villa, y que, por tanto, se veían obligados a desplazarse a la ciudad de Braga ${ }^{44}$.

Por tanto, el proveedor se declaraba afecto a las directrices impuestas por las autoridades, demostraba que las estaba aplicando en la Misericordia, denunciaba las prácticas de la Misericordia de Viana y mostraba cierta preocupación por su falta de respeto a los compromisos contraídos. Seguramente, en su interior, él también deseaba ver disminuido este encargo.

Ya en 1760 había salido a la luz una norma que prohibía la concesión de cartas de guía a aquellos que no presentasen el "bilhete de Identidade Geral da Polícia, com que se legitime". Había comenzado un proceso de persecución a los considerados falsos pobres, que fue ganando fuerza con el avance del siglo XIX. La valorización del trabajo y de la producción individual resultaban claramente

${ }^{43}$ Arquivo Municipal de Ponte de Lima, Livro dos Acórdãos da Câmara de Ponte de Lima 17681771, fl. 136v.

${ }^{44}$ ASCMPL, Livro do copiador $\mathrm{n}^{\mathrm{o}} 27$. 
perjudiciales para el grupo de hombres acusados de ser "fingidores, malfeitores e criminosos", de abandonar el trabajo y de actuar contra el bien común ${ }^{45}$.

El freno que se estaba imponiendo por parte de las autoridades a la prestación de ayuda a los viajeros por parte de las Misericordias, estaba asociado, básicamente, a la expedición de cartas de guía a individuos que ni estaban enfermos ni presentaban el pertinente pasaporte. Sin embargo, las ofrecidas a los enfermos no sólo eran consentidas sino que se consideraban una ayuda necesaria. La legislación favorecía los intereses de las Misericordias que, en muchas ocasiones, se veían abrumadas por los enormes gastos en el tratamiento a los enfermos a los que tenían que enfrentarse. Por tal razón, algunas de estas cofradías amenazaron con no recibir enfermos con cartas de guía, alegando que cada Misericordia debería cuidar de sus naturales.

A pesar de los recortes en esta forma de caridad, las Misericordias continuaron practicándolas. En 1853 llegaba a la institución María de Jesús, natural de la feligresía de Seare, en el concejo de Ponte de Lima, una joven que sufría importantes perturbaciones mentales. La moza se hallaba "divagando, causando prejuizos e tornando-se incomoda aos povos", razón por la cual su madre solicitó a las autoridades de la villa que la recluyesen en la cárcel. Al estar prevista tal medida por el artículo 249 del Código Administrativo, ésta fue llevada adelante. Pero rápidamente se percibió lo inadecuado de esa acción contra aquella muchacha, cuya necesidad era la consecución de un adecuado tratamiento para el que padecía. El hospital de la Misericordia no ofrecía unos servicios tan especializados. Por ello, fue necesario enviarla al hospital de San José de Lisboa, para ser allí tratada. Pobre y sin recursos suficientes, la madre acudió a la Misericordia de Ponte de Lima para que le diese una solución para el transporte de su hija hasta la capital. La Santa Casa no renunció a auxiliarla pero no estuvo dispuesta a hacerlo en solitario. Por esa razón, sugirió que, al no estar contemplados los casos de esa índole en sus estatutos, se debía actuar como con los beneficiados con la carta guía; es decir, que las limosnas fuesen "abonadas de Misericórdia em Misericórdia" ${ }^{46 "}$. De esta forma fue como Maria de Jesús consiguió llegar a Lisboa.

¿Cuánto gastaban las Misericordias en la ayuda de los viajeros? La pregunta no tiene una fácil respuesta y se encuentra siempre condicionada por la producción

45 Sobre la propuesta de De Lima Bezerra para acabar con el vagabundeo y aumentar la productividad de los campos, consultar De Lima BezerRA, M. (1992). Os estrangeiros no Lima. Viana do Castelo, vol. 1, pp. 258-260.

${ }^{46}$ ASCMPL, Livro do copiador $\mathrm{n}^{\circ} 27$, fls. 166v.-167. 
documental. Y es que no siempre es posible cuantificar esos montantes, dado que muchas cofradías no registraban este tipo de ayudas de manera aislada en sus libros de cuentas, integrándolas con otras limosnas. Los gastos para esta forma de caridad eran muy variados y dependían del montante que la cofradía decidiera invertir en este sector. Aún así contamos con algunos ejemplos ilustrativos: en 1641, la Misericordia de Peniche gastaba un total de 1.770 reales en cartas de guía ${ }^{47}$. Por su parte, en la Santa Casa de Setúbal, las cartas de guía y las limosnas representaban el $3,7 \%$ de sus gastos entre 1500 e $1755^{48}$.

Un porcentaje muy semejante fue el alcanzado por la Misericordia de Vila Viçosa. La Santa Casa de esta villa tenía, igualmente, como práctica enraizada e despacho de este tipo de documentos. En 1770, los gastos efectuados en este concepto representaban el 3,4\% del cómputo general de gastos de aquel año ${ }^{49}$. No obstante, se verificaba una gran oscilación en términos de representación mensual. En el mes de julio, la Santa Casa expidió apenas el 1,2\%, mientras que en diciembre el porcentaje subió hasta representar el 5,8\% de los gastos de aquel mes. Las variaciones en los gastos de este tipo estaban asociadas a la demanda de estas ayudas pero también a las opciones de gestión de la propia cofradía. En el invierno, los desplazamientos eran, desde luego, más penosos por lo que las demandas de ayuda se incrementaban. Por otro lado, los hermanos se mostraban más piadosos y concienciados y, por tanto, atendían más peticiones, demostrando estar atentos a las necesidades de los que se beneficiaban.

Los desplazamientos se efectuaban hacia los concejos y tierras circundantes de la villa que, de igual modo, contaban también con sus propias Misericordias donde renovar la carta de guía; ese es el caso de las de Alandroal, Borba o Terena.

En junio de 1771 fue despachado un pobre con carta de guía y cabalgadura para más lejos. En esta ocasión, la cofradía aseguraba el transporte hasta la villa de Redondo a un "pobre sego" ${ }^{50}$. Incapaz de poderse trasladar por si mismo, dada su minusvalía, la cofradía le concedió un transporte animal así como un hombre que lo condujera hasta aquella localidad. A diferencia de este ciego, otros eran

47 Ferreira, F. M. (1997). A Santa Casa da Misericórdia de Peniche (1626-1700). Subsídios para a sua história. Peniche: Santa Casa da Misericórdia de Peniche, p. 251.

${ }^{48}$ Faria Dos Santos Abreu, L. (1990). A Santa Casa da Misericórdia de Setúbal de 1500-1755: aspectos de sociabilidade e poder. Setúbal: Santa Casa da Misericórdia de Setúbal, p. 70.

49 Archivo de la "Santa Casa da Misericórdia de Vila Viçosa" (ASCMVV), Cadernos de receita e despeza 1770.

${ }^{50}$ ASCMVV, Cadernos de receita e despeza 1770, mes de junio, fl. 7vto. 
enfermos, que salían del hospital de Vila Viçosa o estaban de paso, desplazándose de Misericordia a Misericordia.

Los gastos invertidos en cada hombre variaban. Junto al pasaje, las Misericordias solían conceder una limosna a los portadores de las cartas de guía. La Santa Casa de Vila Viçosa concedía una ayuda de veinte reales a cada pobre. Si el enfermo salía de la villa en cabalgadura el gasto del auxilio se incrementaba, variando de acuerdo con el tiempo efectuado en el viaje.

\section{CONCLUSIONES FINALES}

Instrumentos fundamentales para los peregrinos y viajeros, las cartas de guía adquirían status de obra de misericordia y se convirtieron en un instrumento muy solicitado a lo largo de la Edad Moderna. Sin ellas, muchos pobres se verían imposibilitados a efectuar los viajes que necesitaban realizar. Las Misericordias al proveer a los necesitados con esta limosna, posibilitaron la cura de muchos enfermos, así como la realización de viajes, transformando las cartas de guía en verdaderos "pasaportes de caridad". 